\title{
REJUVENATING PEDAGOGY FOR ENGLISH LANGUAGE TEACHING: FIVE INDISPENSABLE FUNDAMENTALS FOR ENGLISH LANGUAGE COMPETENCE IN INDIA
}

\author{
Dr. Richa Tripathi \\ Department of Applied Sciences \& Humanities \\ JIMS, Greater Noida, UP, India
}

\begin{abstract}
Pedagogy of the English language is limited to the prearranged syllabi mostly taught within the classroom boundaries for decades. Globalization and technological advancements have changed the mathematics of Education. Teachers now have a comprehensive set of learners' centric pedagogies to explore and the English language teaching/learning method is also no exception to it. The English Language is a known global language due to digital technology. Now the change is the new constant requirement. Teachers of English language belong to the government and non-government Universities and colleges hold a greater responsibility and duty to nurture students with a wide-ranging set of indispensable skills, immeasurable knowledge, and proficient holistic competency. This study encompasses the five innermost fundamentals of English language teaching/learning which must be covered by every educator, instructor, trainer, and teacher to prepare every college student for providing outcome-based lifelong competency of English Language. These five fundamentals are 'Grammar \& Vocabulary', 'Online/Digital Platforms for Electronic Learning', 'English Language Laboratory Activities', 'Personality Development, Soft Skills and Critical Thinking Skills' and last but not least 'Congruity between Visual, Verbal \& Vocal Cues'. This paper reveals all necessitates of these fundamentals for English Language teachers which should be the part of pedagogy for English language teaching to make students the most efficient in communication and to prepare them for exploring global opportunities.
\end{abstract}

Keywords - Grammar \& Vocabulary, Online/Digital Platforms for Electronic Learning, English Language Laboratory Activities, Personality Development, Soft Skills and Critical Thinking Skills

\section{INTRODUCTION}

In India, there is a need for serious reform of the education system. Teachers must come out from the routine classroom pedagogy which is centered towards timely completion of the syllabus. The biggest driving force for this type of regular mindset is undoubtedly marks and numbers centric teaching where knowledge and learning come secondary and thirdly. Teachers have the pressure to perform rather than educate students. Everything is revolving around a circle where no one is at fault and everyone is at fault. When it comes to language learning, the English language is unquestionably an unbeatable winner. In India, this trend has become a necessity from a fashion or social status symbol because global opportunities come with English language learning at the major level.

English language teaching is embryonic all the time, so the constant changes are required. The teacher's role is not limited to, teaching as the digital online social media tools are gaining popularity. The teacher is a role model, guide, supervisor, advisor, consultant, coach or motivator for students. When it comes to English language teachers, the exam is even tougher. English is a second language for Indians. History is associated with the language so the challenge is even bigger. English language teachers face many difficulties while dealing with students' different levels of requirements. Students face a common area of improvements such as incompetency in language skills, insufficient command over vocabulary and grammar, ineffective communication skills, the incongruity between verbal and nonverbal cues, lack of proper practice or proper guidance for verbal activities, insufficient technological facilities, etc. and many more. This study covers all the requisites to overcome these barriers. By being aware of the five fundamentals, teachers of English language can transform their students into a successful user of Standard English language by adding the right balance between technology, knowledge, language, personality, and communication. It is important to cover topics falling under these five fundaments completed step by step 
each semester or every year, so final year student of the university and college will find it easy to successfully get ahead of the challenges related interviews, group-discussion, debates, meetings, chats, group-talks, presentations, Publics speaking and many more platforms to ex [press views, opinion, feelings, emotions, information and massage. Five fundamentals are as follows

\section{Five Fundamentals of English language Pedagogy}

\section{Grammar and Vocabulary Mastery \\ 2. Online/Digital Platforms for Electronic Learning \\ 3. English Language Laboratory Activities \\ 4. Personality Development and Soft Skills \\ 5. Congruity between Visual, Verbal \& Vocal Cues}

\section{GRAMMAR AND VOCABULARY MASTERY}

If one wants to be knowledgeable, one should gather the authentic information and facts about the domain. Similarly, one can be capable to speak the English language through active listening but the fineness and limpidness will come with the grasp of the Grammar. We cannot neglect the fact that English language learning cannot be error-free without grammar competence. Linguistic competence comes with grammar competence. The necessity of grammar teaching and its significance in language learning should not be the topic for the argument as grammar plays a very specific contribution and real effect on all the four skills of language known as LSRW (Listening, Reading, Writing, Speaking). Grammar is the base of the English language so grammar learning is necessary. To give the English language pedagogy a holistic approach, English teachers must involve grammar and vocabulary practices in the teaching/learning process for communicative proficiency. After completing the school, newly admitted college students are in a strong need to do revision and practice of grammar prior to learning the official and formal communication. Here are the undeniably and an unquestionable portion of the grammar which must be taught to them by the English language teachers. Teachers sometimes have this wrong impression that they are not there to teach grammar from the basic but communicative competence in English cannot be taught without revising these topics. The Same is applicable in Vocabulary skills. As David Wilkins (1972), a British linguist, puts it, "without grammar little can be conveyed, without vocabulary nothing can be conveyed." Teachers must work on the strong base of grammar before teaching them how to express and what to express. Language proficiency will come if the teachers will rework on students' grammar by focusing on these necessary topics.

A. Grammar

- Parts Of Speech

- Tenses

- Subject-Verb Concord/Agreement-
- Active Voice and Passive Voice-

- Question Tags and Shorts Responses-

- Conditional Sentences-

- Articles

- Direct and Indirect Speech

B. Vocabulary

- Synonyms \& Antonyms

- Prefixes \& Suffixes

- Homophones, homonyms

- One-word substitution

- Phrasal verbs

- Idioms and proverbs

\section{Parts Of Speech}

Every English Language Teacher must cover some elements of English Grammar prior to English language speaking and writing practice for college students in higher studies. Parts of speech are known as the building blocks of the English language. One cannot use any English word without knowing its function in the sentence, which can be crucial for maintaining an active dictionary of a human brain with which one actively using the terminologies. All words in the English language are classified under eight different parts of speech. How words can and should be joined together to make sentences that are both grammatically correct and readable, understanding of POS is a must. The eight parts of speech are nouns, pronouns, verbs, adjectives, adverbs, conjunctions, prepositions, and interjections. Without parts of speech, there would be no sentences and no language.

- Noun

- Pronoun

- Adjective

- Determiner

- Verb

- Adverb

- Preposition

- Conjunction

- Interjection

\section{Tenses}

The teacher should pay a lot of attention to tenses in English instruction as they are the root of Sentence construction. It is necessary to give students an overview of the entire verb system in different time frames. The focus should be on only one tense at a time with a lot of practice through exercises during revision in higher education followed by other tenses in that frame. When introducing these tenses, stay in one tense at a time, practicing its form and meaning, as you would have before, but keep showing the tenses in relation to each other, keep referring back to the chart. The application is done best in context. Students cannot read, write or speak properly 
without getting a revision of it for error-free application of tenses in the sentence formation.

- Present Tenses-

- Past Tenses

- Future Tenses-

\section{Subject-Verb Concord/Agreement-}

The teacher must include this part for revision if he wants students to read, write, speak and listen to correct Standard English. When we use the word in the context of grammar, it has a similar meaning: the grammatical agreement between two parts of a sentence.

Important language skill is to have mastery in subject-verb concord. This section of grammar is essential to look up to as it is expected from college students to apply the correct verb with the subject. The subject-verb agreement is no exception to the complex rules of English grammar. A basic error in sentence formation leads to mockery and humiliation. The subject-verb agreement is all about numbers and handled the situation where the verb form is chosen that should match up with the number of things on the subject.

- I don't understand the assignment.

- Sugar and flour are needed for the recipe.

- Neither gray nor white is my favorite color.

- $\quad$ Each gets a medal for playing.

Active Voice and Passive Voice-

The Sentence can be formed active- In speaking, the speaker can put the expression anywhere by shifting the emphasis. Usually, sentences are formed as active voice as they are easy to understand, but sometimes it is better to use the passive sentence as passive voice is used when the focus is on action or object rather than subject. The making of passive sentences from active requires a different set of rules. The teacher must ensure that students are aware of them prior to speaking. For example-

- Active Voice - he does not cook food.

- $\quad$ Passive Voice - The food is not cooked by him.

- Active Voice - Priyanka gave me flowers on my birthday.

- Passive Voice - I was given flowers by Priyanka on my birthday.

\section{Question Tags and Shorts Responses-}

During the conversation, it is obvious to make a statement and then ask for confirmation. To increase the options of putting one's idea in a different manner, Question tags must be known to the English language learners. Question tags are the short questions to clear a suspicion or doubt that we ask at the end of sentences - particularly in spoken English. There are lots of different question tags, but the rules are not difficult to learn. A tag question is a short question added in a statement with a specific set of norms. Question tags can be used during less formal settings among peer groups. The teacher can give the idea to students about how to make question tags in their oral and written expressions. English speakers use tag questions to encourage a listener to respond. For Example

- it is raining, isn't it?

- He can speak English, can't he?

- Jonathan broke the glass, didn't he?

\section{Conditional Sentences-}

During conversations, certain expression comes with conditions in the sentences. Generally, people use If sentences, but with wrong applications of the verb in it which changes the entire meaning and essence of the sentences. The teacher must include this section to avoid any grammatical errors in the conditional sentence formations. Students should practice using conditional sentences for gaining better quality sentences and with the best possible clarity in it.

- If you hurry, you will reach there on time.

- I would travel around the world if I won the lottery.

- When the water reaches 100 degrees, it boils.

Articles: -

Articles play a very integral part of English Grammar as articles are words that define a noun as specific or unspecific. But the crucial thing is that very few speakers are using them correctly. An article is a kind of adjective that is always used with and gives some information about a noun specific or unspecific. English language Teachers must teach articles to students as there are lots of rules about the use of articles. This grammatical concept may sound simple, but there are some tricky rules related to using it correctly and most users of the English language ignore this due to the complexity.

- Definite Article (The)

- Indefinite Article ('A' and 'An').

\section{Direct and Indirect Speech}

Information can be sometimes directly quoting a speaker, while other times translations of the original speech into our own words. Telephonic conversations are based on direct speech as people hear an indirect narration of the story. Direct and indirect speech can be a source of confusion for English learners. Converting speech from direct to indirect is necessary to know for English Language teachers to teach students to gain command over English.

- Direct: He says, "Jacky kills a rat."

- Indirect: He says that Jacky kills a rat.

- Direct: He said, "I am a cricket player."

- Indirect: He said that he was a cricket player.

Vocabulary:-We think through words and without words, it would be impossible to feel and express in a well-thought-out way. Even when we think during intrapersonal communication, most of it is unsaid but through silent words 
floating in our minds. According to Spender (1980) believes, 'In order to live in this world, we must name it as globe, earth, planet. Names are essential for the construction of reality. Without a name, it is difficult to accept the existence of an object, an event, a feeling. Naming is the means whereby we attempt to order and structure the chaos and the flux of existence which would otherwise be an undifferentiated mass. By assigning names we impose a pattern and a meaning which allows us to manipulate the world'

Whenever we think about language, words come to our minds first and words are the base of vocabulary building. The Longman Dictionary of Contemporary English (2000) defines vocabulary as, 'All the words that someone knows, learns or uses'. As per Cameron, Vocabulary, as one of the knowledge areas in language, plays a great role for learners in acquiring a language. Vocabulary can be defined as " words, we must know to communicate effectively; words in speaking (expressive vocabulary) and words in listening (receptive vocabulary)"

Teachers must aware of students about this one of the major fundamentals for gaining mastery of the English language. Students can expand their vocabulary by not just being about a term and its meaning, but also should use it on a daily basis. Reading comprehension, listening comprehension, speaking, writing, spelling, and pronunciation depend on vocabulary skills. Even students can expand their knowledge of vocabulary without being dependent on anyone as online and digital platforms are very helpful in it. Schmitt (2010) quoted that, "learners carry around dictionaries and not grammar books" consequently, lexical mastery is important when one wants to get expertise in a second or foreign language. There are several elements that must be in control to play with words intelligently. The role of vocabulary is crucial while selecting appropriate words.

\section{$>$ Synonyms \& Antonyms \\ $>$ Prefixes \& Suffixes \\ $>$ Homophones, homonyms \\ $>$ One-word substitution \\ $>$ Phrasal verbs \\ $>$ Idioms and proverbs}

One can even survive with the limited knowledge of vocabulary, but mastery comes with wider knowledge and that is why one should put constant efforts to enrich one's vocabulary. Teachers can help students by including them in their conversations, by giving assignments, projects and oral activities so that their knowledge of words expands continuously.

\section{DigitAl PLATFORMS AND ENGLISH LANGUAGE}

In the technology-driven world, English language teachers should not only utilize these electronic learning podiums to constantly advance and upgrade their teaching methods, but also they should not hesitate to suggest, guide and supervise students about exploring these E-learning means so that students can find various ways to clear their concepts, remove their doubts and to learn unstoppable without being restricted by money, time and place. Mobile phones, gaming laptops, tablets, computers, notebooks and the availability of cheap the internet makes the learning and unlearning very easy for anyone who is curious to know. When it comes to English language learning, we find tremendous means to expand learning and modify teaching pedagogy. These means can be explored inevitably such as

- Online Dictionaries and Vocabulary Tools

- Computer-assisted Software and mobile Applications-

- Digital Audio Books

- YouTube Videos -

- Online Cinema and News

- Online Communication tools-

- Online Games

- Web sites and blogs

- Online Courses

- Online Social Networking Platforms

\section{Online Dictionaries and Vocabulary Tools}

English words which are mispronounced due to lack of right source and knowledge and awareness to know the right pronunciation of particular words. Teachers must suggest students to install online/offline dictionaries in their mobile phones which provide the facility of audio, video, written modes of imparting information related to any random word with its multiple meanings, different examples of sentences, various parts of speech, synonyms and antonyms, and audio for the correct pronunciation. Collins English Dictionary, Reverso, Cambridge Advanced Learner's Dictionary \& Thesaurus, Oxford Learner's Dictionaries Online, Longman Dictionary of Contemporary English Online, MerriamWebster are few best-known titles in the pitch.

\section{Computer-assisted Software and mobile Applications}

Various applications and programs which are based on correct usages of grammar, punctuations, sentence formation, right application of word and phrases in correlation with expression etc. Installation is very easy, fast and cost-effective. These applications, such as Tense Buster, Study Skills, Beat The Clock, Words Worth English, Vocabulary builder is an engaging, interesting and fast way to learn and work on errors present in the English language. Educational Institutes must have them in the computer systems of Language Laboratories for students' practice and learning.

\section{Digital Audio Books}


Recent trend digital audio books prove the very innovative and unconventional method to improve English language learning anywhere, anytime as companies like Apple, Samsung, etc. are developing and making separate gadget only for e-book specifically designed for active reading and listening. The audio books improve fluency, Comprehensive skill, pronunciation skills of English as a foreign language or English as a second language covering different proficiency levels of learners. One of the major multimedia tools certainly work as an encouragement for teachers along with students to seek different ways of learning/teaching English. Audible, Project Gutenberg, Librivox, Local Library is a popular platform to find a huge collection of audiobooks.

\section{YouTube Videos -}

English language learning has become very easy, convenient, error-free and filled with various choices due to YouTube as the English teachers, trainers and educators can upload videos as per the demand of the learners and students. It covers all types of communication such as oral, visual, written, spoken, audio, electronic, print, picture-oriented, presentation, etc. It is a platform to enhance four pillars of language learning, reading, writing, speaking, and listening. The learner can search for specific videos related to learners' specific needs in terms of time, content, lesson, communication, language, and other requirements. YouTube has a lot of English language lessons and English language learning channels based on every single aspect of the English language that is available for free. YouTube is filled with so many channels such as the British Council Learn English, Anglo-Link, Learn English through Hindi, EnglishLessons4U, and Let's Talk, etc.

\section{Cinema and News}

English movies, English songs, English web series, English Television Shows are an integral part of everyone's life nowadays, so it will be a realistic approach if the teacher will include them in their teaching-learning methods. With the help of these methods of Cinema and media industry, teachers can help student for creating such a learning environment where they can watch and listen to the content while focusing on reading and listening to English language. The learner should select the mediums as per their interest among movies, songs, TV serials, web series, chat shows, debates, documentaries, news reports, etc. Here are some good suggestions for English movies, shows and serials to give power to the English language which can be shown to Indian college students during language lab activities as well as one can follow them individually such as Twelve Angry Men, Forrest Gump, Mega Mind, Monster University etc.

\section{Online Communication tools-}

E-mail, Instant Messaging, Messengers, What's App, video conferencing applications like Skype, chat rooms and blogging tools are platforms to learn and practice English language for formal and official correspondence. Teachers can deliberately establish written communication with the students through these technical mediums and ask them to submit assignments, projects, applications, letters, reports, etc. Through these mediums one can easily trace out mistakes, highlight them and can give their remarks for improvements. These communication tools enriched with the facilities of sharing spoken, written, visual, audio, pictures, video content at a mass level. It is a very strong medium to learn through interaction with one another by using these communication tools.

\section{Online Games}

Due to mobiles, online games have become addictive trends among school or college students. Language learning has become a piece of cake through online gaming as it provides specifically designed games to standardize the English language. Teachers can ask students to download these games based on various aspects of the English language for practicing regularly. The Grammar of Doom from Game Zone, Wordshake, FluentU, ESL Crossword Puzzles, Freerice, and Scrabble Online is online platforms for this.

\section{Web sites and blogs}

Various search engines are filled with the results of enormous websites that offer either free or chargeable access to material and content worked under the guidance of government and non-government organizations to contribute fully to the education sector through correspondence. Every website for English language learning is different in terms of teachinglearning methods, time commitment, purpose and scope of the study, coverage of specific skills, diverse topics and materials, medium for communication, etc. By taking the help of these websites, teachers can unlock enormous ways and materials to enhance their teaching process and they can modify them on a regular basis to avoid boredom created due to monotony. The detailed and well-structured lesson plans, curriculum, syllabi, quizzes are present in websites like www.learnenglish.britishcouncil.org, www. britishcouncil.org, www.learnrealenglish.com, www. englishcentral.com, etc.

\section{Online Courses}

Real university professors, experts and specialists are teaching enormous national and international students through these courses affiliated to reputed and well recognized government and non government organizations They issue e-certificates to the enrolled students who successfully completed the courses and given the exam which is required. These online options for English learning is designed in such a way to help thousands of aspiring English speakers in their quest to speak English correctly, fluently and confidently with the facilities of virtual Classes, video conferencing, Speaking, Listening Comprehension followed by Certificates to open Online job opportunities for fresher \& job seeker. NTPEL, SWAYAM are known portals for online courses. 


\section{Online Social Networking Platforms:}

Who doesn't know the names of Face book, Instagram, Snapchat, Twitter, LinkedIn, Quora, Pinterest, Tumblr, My Space, Google + in current modern society? People across the world are using these social networking websites for socialization. This wide-ranging platform has become a substantial medium to communicate and connect people to spread awareness and knowledge. These platforms have become a very strong medium between teacher and students for remaining connected throughout lives and to be familiar with the opinions. This can be used as increasing the understanding of English Language such as knowing the advanced and popular trendy use of English terminologies, sentence the formation, selection of words, phrases and clauses, etc.

\section{LANGUAGE LABORATORY ACTIVITIES AND ENGLISH LANGUAGE}

Pedagogy for English Language teaching is incomplete without language lab activities. Any language is meant to be spoken and written, writing skill comes with greater command over grammar and vocabulary which results in well-written competency. Conversely, the requirement for oral communication is without doubt spoken practices. It is a must when English is taught as a foreign or second language. Teachers can facilitate the learning of the English language by conducting some activity-based practices where students find a supporting environment, inspiring co-operation and motivation to practice English speaking without too much thinking and hesitation. The sequential pattern of the activity will enable a teacher to uplift the overall contribution of every participant diverse in a level of understanding and knowledge. This section discloses necessitates of the fourth fundamental which must be practiced during the language laboratory activities step by step.

The ideal sequence of Language Lab activities while practicing the English language

\section{$>$ An Icebreaker Activity \\ $>$ Self Introduction \\ $>$ Interactive Question Answer \\ $>$ Prepared Speech Delivery \\ $>$ On the spot Speaking \\ $>$ Role Plays \\ $>$ Group Discussions \\ $>$ Presentations \\ $>$ Mock Interviews}

\section{An Icebreaker Activity}

To begin with, such activity is an excellent move as it involves everyone in the group of students who took it as a group task, activity or challenge which is any random fun, interactive, engaging and interesting activity, game, or event specifically designed by the teacher according to their students and their proficiency level. For example, Vocal warm-up exercises, Predictions based on first impressions, One-minute life stories, Concentric Circle Conversations, Name Acrostics, Two Truths One Lie, Personality Quiz, Sharing of my Bucket List, etc.

\section{Self -Introduction}

'Self Introduction' as the term suggests shows students' ability to introduce you in public and the ability to have good communication skills in the English language and to show self-confidence. How to introduce yourself is extremely important to create an excellent impression based on selfintroduction not only for interviews, meetings, public addressing, group discussion, debate, presentations, etc. The introduction must contain information such as name \& place, academic details, Interests/hobbies, strengths and two areas of improvement, future goals in life, etc.

\section{Interactive Question Answer}

'Interactive Question Answer Session' will be the perfect activity that provides the setting for students to mingle and open up at the individual level in a team of English language learners. By giving some situational, imaginary and ingenious questions to the students, the teacher can help them to answer without hesitation and to develop the quality to give creative and solution-based answers with logic and sense, to improve listening skills and on the spot thinking ability, to achieve the goals, etc. Questions can be based on any genre such as movies, books, novels, personal difficulties, favourite things, favourite personalities or celebrities, based on diverse temperaments, life-based situations, achievements, to-do lists, any dream come true moments, etc.

\section{Prepared Speech Delivery}

The activity of 'Prepared Speech Delivery' prepares students for public addressing but also provides an opportunity to think, analyze and redefine the ideas on the specified topics. Proper planning, preparation, and practice make the speech impactful, approachable and appealing to the audience. This practice prepares students for collecting important information gathering them, organizing them in proper order and then focusing on impactful and approachable content delivery verbally as well as non verbally. The teacher must cover social, political, financial, moral, national, international and global issues related to education, government and the law, health, media, arts/culture, economic, ethics, religion, environment, science, and technology, etc.

\section{On the spot speech Deliveries}

Teachers must conduct this activity with students to enable them to handle the spot speech delivery situations as leaders, professionals, and entrepreneurs have to face unplanned and random situations to deliver a view without preparation. This activity, students to think very quickly with reason and logic, to develop good communication skills consecutively and to master in handling discussion on random topics, issues, and 
domains. Debate, interviews, meetings, discussion in groups are also some regular basis activities in which participants should have command of their cognitive, communication and presentation skills.

\section{Role Plays}

The Role Play is a perfect activity to master a combination of knowledge, language, deep emotion and clarity of expression. This practice will certainly develop their ability to handle emotionally difficult conversations such as conflict resolution and handling perplexing situations in a particular given situation and to develop their cognitive capacity for logical verbal counter-arguments. Nukkad Natak and Drama are proving helpful in the English Language Laboratory because these activities provide a platform to the learners for representing their reasoning, logic, illustrations, examples, data, facts and figures strictly in the English Language. Situation based role play is a good choice, for example, the scene based on the arguments between shopkeeper and angry customer, old grandfather, and granddaughter, fuming owner and tenant, doctor and difficult/vulnerable patient, etc.

\section{Group Discussions}

'Group Discussion' plays a very vital role in English language learning among language learners as it enhances the multidimensional cognitive skills, listening skills, and speaking skills at the same time. These discussions are helpful in making decisions rapidly; give scope to share views and ideas, to resolve a problem and to analyze a situation and to provide recommendations and conclusions. It assesses behavioral traits, leadership skills, social skills, team skills, problem-solving skills, confidence level, knowledge, social awareness, communication skills, and cognitive capabilities. Topics may be debatable, such as god exists or not, internet: curse or boon, love marriages versus arranging marriages, humanistic approach or materialistic approaches, etc.

\section{Presentations}

Presentation skills are an impressive and powerful activity that will take you so much further than just speaking in the classroom. With proper communication skills training in the English language, the teacher should focus on making students a good presenter with the ability to structure and express ideas clearly. Know good presentation strategy empowers presenter in building good rapport among receivers, to establish a powerful candidature in job interviews and in meetings, social settings, conferences, seminars, etc. Presentation strategies include some major aspects such as its purpose, audience, locale, content, outlining, audiovisual aids, nuances of delivery, paralinguistic feature, and kinesics, etc.

\footnotetext{
Mock Interviews

'Interview skill and mock session' which boosts confidence in students to face dissimilar challenges present in different kinds of interviews. Most students are clueless due to lack of
}

practice and preparation and they feel fear, hesitation, and lack of confidence to reply in English in spite of being aware of the correct answers. All barriers must be omitted through proper planning, practice, and preparation. The teacher can ask students to perform as both interviewer and interviewee during a mock session so that they can understand both sides as an interviewee as well as the perspective of an employer to hire a candidate and the need to satisfy those expectations as an interviewee. This process has real-world experience interviewing job candidates. For the best results in the future, the teacher must help in giving guidance to the students to be unbeatable in their communication in English, attitude, confidence and cognitive abilities.

\section{Personality DeVElopment, Soft Skills AND CRITICAL THINKING SKILLS}

English is undoubtedly world's Lingua Franca, many Indian students perusing higher studies now focusing on learning English to gain communicative proficiency and competency. The duty of the English language teacher associated with government, semi-government and non-government organizations and universities is to expand and go beyond the narrow boundaries of the prearranged repetitive syllabi and to enlarge their circle by including grammar, e-learning options, language lab activities on miscellaneous topics for developing personality, enhancing soft skills and critical thinking abilities, etc. This section sharpens the edge of knowledge, language and expression among students by including enormous topic that helps students dealing with the practicality of the situation, circumstances, and problems. In India, Employment issues are the matter of great concern and bigger care and responsibility are associated with it. Most job seekers in India are not finding jobs due to poor English, ineffective personality, lack of soft skills and critical cognitive skills. Hard Skills are nothing without these special skills which diverse as creativity, time management, problem-solving and emotional intelligence. According to Wikipedia, "Soft skills are a combination of people skills, social skills, communication skills, character or personality traits, attitudes, career attributes, [1] social intelligence and emotional intelligence quotients, among others, that enable people to navigate their environment, work well with others, perform well and achieve their goals with complementing hard skills.[2] The Collins English Dictionary defines the term "soft skills" as "desirable qualities for certain forms of employment that do not depend on acquired knowledge: they include common sense, the ability to deal with people, and a positive flexible attitude." No one can deny this fact that in today's digital world, one cannot survive in the long run without empowering oneself with these necessities. Not only obtaining a good academic qualification is necessary but presenting and expressing them visually, verbally and vocally is equally essential. Securing positions in the highly competitive era require these fourth fundaments to be included in the pedagogy at college or individual level by the teacher. 
A. A New Approach to Education and learning

B. Planning and Goal-Setting

C. Personality and Mindsets - An Explanation; Categories of Personality Types of People, Definition, Types, Learning mindsets, and Secrets of Developing Growth Mindsets, Human Perceptions

D. Self Realization and Self-Management-Aiming For Excellence: Developing Potential and Self-actualization

E. Anger Management- Analyzing Reasons and Controlling Anger,

F. Positive and Negative Thinking and Humour- Humour in Communication, Humour in the Workplace, Function of Humour in the Workplace

G. Interpersonal Skills- Human Relations: Developing Trust and Integrity Understand Self - Different Categories; Diagnosis of Type of Self Identifying own type of self; Effect of Interpersonal Behaviour of Interpersonal Relationship

H. Communication Skills- LSRW -Meaning, types, levels, flow, Barriers to Communication

I. Stress Management - Causes of Stress and its impact, how to manage \& distress, Circle of control, Stress Busters.

J. Time Management- Importance of Time, and Understanding Perceptions of Time, Chronemics, Dos and Don'ts, Importance, perception, Utilization and Overcoming Procrastinations

K. Technology and Communication: Netiquette, E-Mail Etiquette, Mobile Personality

L. Habits- Guiding Principles, Identifying Good and Bad Habits, Habit Cycle

M. Presentation Skills and its important strategies

N. Reasoning and Aptitude

O. Confidence, Motivation and Creative Thinking

P. Leadership Skills, Team Building, Group Dynamics-

Explanation; Role \& Functions of a Good Leader;

The criticality of Team Leadership; Traits of

Leadership; Leadership styles, Career Growth

Q. Group Discussion-Meaning, types, requisites, Importance

R. Interviewing Skills- Introduction, Resume Writing, Dress Code, Mock-Interview, How to be Successful in an Interview

S. Conflict Resolution -Conflicts in Human Relations Reasons Case Studies, Approaches to conflict resolution.

T. Self-Management Skills- Who am I, Attributes, Importance of Self Confidence, Self Esteem.

U. Money Management- Money and Personality,

V. Decision Making and Problem Solving abilityImportance and necessity of Decision Making, Process and practical way of Decision Making, Weighing Positives \& Negatives.

W. Morality and Ethics.

X. Intelligence Quotient, Emotional Quotient, Physical Quotient, Spiritual Quotient, Adversity Quotient,
Creative Quotient- Meaning, types need, ways and methods, Importance and balance.

Y. Argumentative and Negotiation Skills.

Z. Health and Personality- Managing Health, Importance of Exercises, Managing Health, Diet and Sleep.

Developing these skills is a dire need for the new bees of future generation who are going to help in building nation because they are going to be the representatives of our country globally if they will get the opportunities.

\section{Non-Verbal COMmunicAtion AND Vocal CuES}

It is the undeniable fact that 'how to say' is as equally vital as 'what to say.' are How to say means the way recipients perceive massage based on visual, vocal and verbal cues. The teacher can help students focus on these important necessitates of the fifth fundamental. Only focusing on subjective knowledge is an ignorant move as one have to learn not only effective verbal and linguistic expression of that knowledge but also non-verbal communication that is established mostly visually. One may sound good but not believable if one is not considering working on their non-verbal communication and vocal cues. Reading body, facial expression, eye movement covers major part of it. Life quality will be much better if one remains aware of it and continuously improving themselves in terms of the way they carry themselves.

This part covers many sections that are still negligible for most of the educator as well as learners. These are numerous in numbers such as

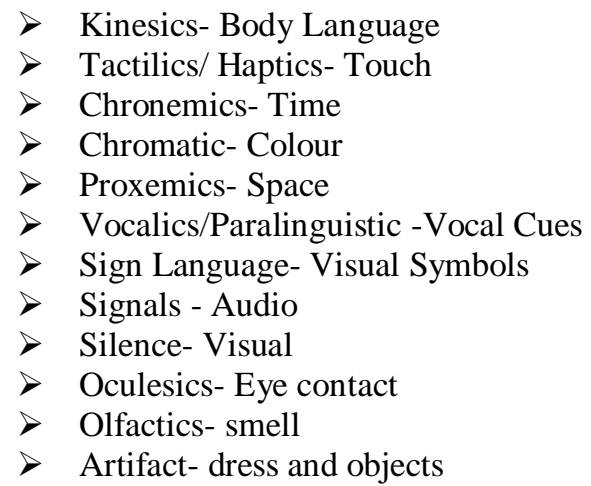

Educator must ensure that learner acquire command on these component as these divisions are clearly visible to establish right kind of impression on others. This certainly gives boost to profession as well as personal life.

\section{CONCLUSION}

This study highlights the major five fundamentals to ensure holistic and all-inclusive approach while dealing with Second language learning of the English language for specific purposes. These five fundamentals and their divisions along with sub-divisions will be verification for the path to move 
ahead in the right direction. These deep-seated guidelines have become the utmost stipulation for the instructor and educator to be familiar with them as without them, one cannot bring the considered necessary change in the learner or student. We cannot close our eyes from today's rations and becoming great communicator is one of the leading require of today's modern technologically advanced era where effective communications is the key to unlock information gathering processing in Artificial Intelligence Era.

\section{REFERENCE}

[1] D. Wilkins, "Linguistics in language teaching", Cambridge: CPU, p. 111, 1972.

[2] D. Spender, and N. Bardin, "Man made language." pp. 163, 1985.

[3] M. Michael, "Ed. Longman dictionary of contemporary English", Pearson Education India, pp. 1599, 2000.

[4] L. Cameron, "Teaching languages to young learners", Cambridge: Cambridge University Press, 2001.

[5] S. B. Neuman, \& J. Dwyer, "Missing in action: Vocabulary instruction in pre-k. The Reading Teacher, 62 (5), p. 385. 2009.

[6] N. Schmitt, "Researching vocabulary: A vocabulary research manual", University of Nottingham, UK, p. 4. 2010.

[7] R. Tripathi "A Discourse on Revitalizing the Role of ELearning : Teaching-Learning Process of English Language in Higher Education of India", CASS Studies multidisciplinary Journal, ISSN:2581-6404, Vol. 3, Issue 1, (Addendum 9 -Special Issue), pp-21-39, May-2019.

[8] R. Tripathi "The Role Of Chronological Pattern in the Progression Of Professional Communication-Language Lab Activities- Improving Effectiveness Of English Language Teaching As A Second/Foreign Language In India", International Journal of Emerging Technologies and Innovative Research, ISSN:2349-5162, Vol.6, Issue 3, page no. pp7-17, March-2019.

DOI: http://doi.one/10.1729/Journal.19991 